\title{
EFEITOS DE ADUBAÇÃO NITROGENADA DE COBERTURA EM MILHO CONSORCIADO
}

\author{
Rebeca Greve de Moraes Scotta ${ }^{1}$, Gilberto Coutinho Machado Filho ${ }^{1 *}$, Joênes Mucci Peluzio ${ }^{1}$, Edmar \\ Vinicius de Carvalho ${ }^{1}$, Michel Antônio Dotto ${ }^{1}$, Flávio Sérgio Afférri ${ }^{1}$
}

\begin{abstract}
RESUMO - O objetivo do trabalho foi avaliar o efeito do consórcio entre o milho, Brachiaria decumbens e feijão guandu (Cajanus cajan) plantados simultaneamente, sob diferentes níveis de nitrogênio em cobertura. O experimento foi realizado no ano agrícola 2011/12 na área experimental da Universidade Federal do Tocantins - UFT, localizada em Gurupi, Tocantins, Brasil. As doses de N foram 0, 40, 80, 120, 160 e $200 \mathrm{~kg} \mathrm{ha}^{-1}$, utilizando delineamento experimental em blocos ao acaso com três repetições e 24 tratamentos. Observou-se que os consórcios não prejudicaram nenhuma das variáveis do milho avaliadas (comprimento de espiga, número de grãos por fileira, peso de espiga com palha e peso de grãos), embora as doses crescentes de $\mathrm{N}$ influenciaram positivamente as variáveis avaliadas.
\end{abstract}

Palavras chave: braquiária, guandu, Zea mays L.

\section{EFFECTS OF NITROGEN FERTILIZATION ON CORN INTERCROPPING}

\begin{abstract}
The objective this study was evaluate effects of intercropping between maize, Brachiaria decumbens and guandu beans (Cajanus cajan) sown simultaneous, under different levels of nitrogen (N). The study was carried out in the harvest season year 2111/12 at experimental area of Universidade Federal do Tocantins - UFT, located in Gurupi, Tocantins Brazil. The N rates were 0, 40, 80, 120, 160 e $200 \mathrm{~kg} \mathrm{ha}^{-1}$, utilized the experimental drawing in random block designs with three repetitions and 24 treatments. Was observation that the intercropping have not effect on corn characteristic length of ear, number grain per row, weigh of ear of maize with straw and weigh of grain, however the crescent levels of $N$ was proportionate influence.
\end{abstract}

Keywords: Brachiaria, pigeon pea, Zea mays L.

\section{INTRODUÇÃO}

O nitrogênio $(\mathrm{N})$ é um dos nutrientes requeridos em maior quantidade pela cultura do milho. Sabe-se da importância do nitrogênio quanto às suas funções no metabolismo das plantas, participando como constituinte de moléculas de proteínas, coenzimas, ácidos nucléicos, citocromos, clorofila e outros, sendo o elemento requerido em maior quantidade pela planta do milho, além de ser um dos nutrientes de maior influência no aumento da produção (Gomes et al., 2007; Duete et al., 2008). A produtividade de espigas de milho pode ser influenciada por uma série de fatores, e dentre eles, destaca-se a adubação nitrogenada (Machado Filho et al., 2018).

Entretanto em muitas situações, o nitrogênio é fornecido em quantidade insuficiente às plantas. Em anos de condições climáticas favoráveis à cultura do milho, a quantidade de $\mathrm{N}$ necessária para aumentar a produtividade de grãos pode chegar a mais de 150 $\mathrm{kg} \mathrm{ha}^{-1}$ havendo a necessidade de usar fontes suplementares deste nutriente, como adubos minerais, leguminosas e estercos, de forma isolada ou combinada (Amado et al., 2002).

\footnotetext{
${ }^{1}$ Pós-graduação em Produção Vegetal, Universidade Federal do Tocantins, Campus Gurupi, Tocantins, Brasil.

*Contato para correspondência: coutinhoagro@hotmail.com
} 
O cultivo em consórcio pode ser definido como um sistema em que duas ou mais culturas, com diferentes ciclos vegetativos e arquitetura de plantas, são colhidas concomitantemente na mesma área (Machado Filho \& Silva, 2013). O consórcio dos adubos verdes (Mucuna anã, Guandu anão, Crotalaria spectabilis e Feijãode-porco) em plantio simultâneo ao do milho pode ser uma prática recomendável, pois não afeta o estado nutricional e a produção de grãos da gramínea, além de evitar uma operação pós-plantio (Heinrichs et al., 2002). Segundo Andrade et al. (2001), sistemas de consórcio entre milho e feijão não afetaram o rendimento do milho-pipoca.

Em consórcios de milho com braquiária, Borghi $\&$ Crusciol et al. (2007) encontraram valores que os permitiram inferir que, em condições de cultivo consorciado, desde que bem realizado, a competição por nutrientes é pequena entre as espécies, independentemente da modalidade de consórcio empregada. Segundo Rezende et al. (2008), o fornecimento de nutrientes em doses mais elevadas pode reduzir eventuais perdas de produtividade do milho, decorrentes de elevada competição interespecífica quando consorciado com outra espécie.

Diante do exposto, o objetivo do presente trabalho foi avaliar o efeito de doses de nitrogênio em cobertura, na cultura do milho, em sistema solteiro e consorciado com feijão guandu e/ou Brachiaria decumbens.

\section{MATERIAL E MÉTODOS}

Os experimentos foram instalados na área experimental da Universidade Federal do TocantinsUFT em Gurupi no sul do Estado de Tocantins com as coordenadas geográficas: $11^{\circ} 43^{\prime} 45^{\prime \prime}$ de latitude $\mathrm{S}$ e 49 $04^{\prime} 07^{\prime \prime}$ de longitude W e altitude de $280 \mathrm{~m}$; com clima do tipo B1wA'a' úmido com moderada deficiência hídrica, segundo a classificação de Koppen, em um Latossolo Vermelho-Amarelo distrófico.

Os experimentos foram instalados no dia 25 de março de 2012 com adubação de $550 \mathrm{~kg} \mathrm{ha}^{-1}$ de NPK na fórmula $05-25-15+0,4 \%$ de $Z n$, sendo o consórcio do milho com a Brachiaria decumbens e o feijão guandu (Cajanus cajan) semeados na linha de plantio do milho. O desbaste manual foi feito 21 dias após a semeadura, para o milho e feijão guandu, com o intuito de obter-se uma população de milho de 50.000 plantas por hectare.
O delineamento experimental utilizado foi de blocos casualizados com três repetições para cada experimento, sendo cada experimento, representado por um tipo de consórcio. Os experimentos foram compostos pelos consórcios: 1: Milho solteiro (MS); 2: Milho com FeijãoGuandu $(\mathrm{M}+\mathrm{G})$; 3: Milho com Feijão-Guandu e Braquiária $(\mathrm{M}+\mathrm{G}+\mathrm{B})$ e 4: Milho com Braquiária $(\mathrm{M}+\mathrm{B})$. Em cada experimento utilizou-se seis níveis de adubação nitrogenada $(0,40,80,120,160,200)$ aplicados aos 21 dias após o plantio, na forma de sulfato de amônio sob boas condições de umidade no solo.

A parcela experimental foi composta por três linhas de seis metros de comprimento espaçadas a $0,75 \mathrm{~m}$ na entre linha. As sementes da leguminosa foram semeadas na linha de plantio do milho para que o guandu pudesse se estabelecer durante o ciclo do milho, as sementes da braquiária, foram colocadas juntamente com o adubo de semeadura. A distribuição do adubo nitrogenado foi feita a aproximadamente $10 \mathrm{~cm}$ das fileiras das plantas, a fim de evitar o contato do fertilizante com as folhas o que poderia provocar a desidratação e morte das células da epiderme conforme relata Kappes et al. (2009), e os demais tratos culturais foram feitos de acordo com o recomendado para a cultura do milho.

As variáveis analisadas foram comprimento de espiga em centímetros (CE), números de grãos por fileira (NGF), peso de espiga com palha em gramas (PECP) e peso de grãos (PG) corrigido para $13 \%$ de umidade. Para produção de grãos (PG) e produção de espigas (PECP), também foram realizadas as análises de regressão para os seis níveis de nitrogênio em cobertura superficial sem incorporação.

Realizou-se a análise de variância individual em cada experimento, e posteriormente, procedeu-se a análise conjunta dos experimentos utilizando o programa estatístico SISVAR (Ferreira, 2011).

\section{RESULTADOS E DISCUSSÃO}

Avaliando a influência das doses sobre todas as variáveis, observou-se significância a $1 \%$ de probabilidade pelo teste $\mathrm{F}(\mathrm{P}<0,01)$, nos consórcios houve influência apenas para número de grãos por fileira (NGF) a 5\%. Ocorreu interação entre dose e consórcio para comprimento de espigas (CE) e número de grãos por fileira (NGF) a $1 \%$.

Não houve diferença significativa para os níveis de adubação nitrogenada com $200 \mathrm{~kg} \mathrm{ha}^{-1}$ e $80 \mathrm{~kg} \mathrm{ha}^{-1}$ 
(Tabela 2), concordando com Carmo et al. (2012) ao dizerem que recomenda-se normalmente entre $80 \mathrm{e}$ $120 \mathrm{~kg} \mathrm{ha-}{ }^{1} \mathrm{de} \mathrm{N}$, alguns produtores têm evidenciado variações e aumentos de produtividade com o uso de doses mais elevadas. Porém a dose de $80 \mathrm{~kg} \mathrm{ha}^{-1}$ não diferiu das restantes, excetuando-se a testemunha $\left(0 \mathrm{~kg} \mathrm{ha}^{-1}\right)$.

No milho solteiro (MS) foi possível observar com maior clareza o efeito do $\mathrm{N}$ em cobertura, pois ocorreu maior número de diferenças estatísticas entre as médias. No consórcio de milho + feijão guandu $(\mathrm{M}+\mathrm{G})$ não houve interferência significativa das doses de $\mathrm{N}$, já em milho + Braquiária decumbens $(\mathrm{M}+\mathrm{B})$ as maiores doses foram as que obtiveram as médias mais elevadas de CE sendo $211 \mathrm{~mm}$ e $180 \mathrm{~mm}$ correspondendo a 200 e $160 \mathrm{~kg} \mathrm{ha}^{-}$ ${ }^{1}$ de N, respectivamente, sendo que esta última não se diferiu estatisticamente das demais. Segundo Cruz et al. (2008) a Brachiaria decumbens não interfere na nutrição mineral do milho, Barducci et al. (2009) acrescentam que quando se deseja obter os benefícios do cultivo consorciado visando à utilização em sistemas de produção como o de integração agricultura-pecuária, um excelente consórcio a ser utilizado é o milho cultivado simultaneamente com Brachiaria, pois a semeadura pode ser realizada concomitantemente sem prejuízo à produtividade. No consórcio entre milho + guandu + braquiária $(\mathrm{M}+\mathrm{G}+\mathrm{B})$ a maior dose $\left(200 \mathrm{~kg} \mathrm{ha}^{-1}\right)$ seguiu a tendência dos demais apresentando média superior.

Dentre os consórcios, o que obteve a maior média de CE foi o milho + braquiária $(\mathrm{M}+\mathrm{B})$ com $178 \mathrm{~mm}$, embora não tenha havido diferença estatística entre esta e as demais médias, estando de acordo Richart et al. (2010) ao obterem resultados que evidenciam a viabilidade técnica deste tipo de consórcio, desde que as duas espécies sejam implantas simultaneamente, pois, desta forma, o cultivo consorciado permitiria a produção de grãos de milho, sem comprometer do estabelecimento da B. ruziziensis.

Tabela 1 - Análise de variância para as variáveis, comprimento de espiga (CE), número de grãos por fileira (NEF), peso de espigas com palha (PECP) e peso de grãos (PG) do milho consorciado com níveis de nitrogênio em cobertura

\begin{tabular}{|c|c|c|c|c|c|c|c|c|c|}
\hline \multirow{2}{*}{ Fonte de Variação } & \multicolumn{3}{|c|}{$\mathrm{CE}(\mathrm{cm})$} & \multicolumn{2}{|c|}{ NGF } & \multicolumn{2}{|c|}{ PECP (g) } & \multicolumn{2}{|c|}{ PG (g) } \\
\hline & GL & QM & $\mathrm{F}$ & QM & $\mathrm{F}$ & QM & $\mathrm{F}$ & QM & $\mathrm{F}$ \\
\hline Dose & 5 & 1632,9 & $*$ & 50,93 & $*$ & 8120,2 & $* *$ & 3386,5 & $*$ \\
\hline Consórcio & 3 & 129,86 & $\mathrm{~ns}$ & 29,85 & $*$ & 1902,6 & $\mathrm{rs}$ & 406,26 & ns \\
\hline Dose*consócio & 15 & 483,24 & ** & 29,25 & $*$ & 1051,9 & $\mathrm{rs}$ & 417,32 & ns \\
\hline Bloco & 8 & 616,9 & & 31,9 & & 844,69 & & 471,18 & \\
\hline $\mathrm{CV}$ & & 7,34 & & 8,92 & & 15,69 & & 15,1 & \\
\hline Média geral & & 175,17 & & 35,61 & & 252,31 & & 154,79 & \\
\hline
\end{tabular}

* e** Significativo a $5 \%$ e $1 \%$ de probabilidade, respectivamente pelo teste $\mathrm{F}$.

Tabela 2 - Comprimento de espiga ( $\mathrm{mm}$ ) para diferentes consórcios: milho solteiro (MS); milho com feijãoguandu $(\mathrm{M}+\mathrm{G})$; milho com braquiária $(\mathrm{M}+\mathrm{B})$; e milho com feijão-guandu e braquiária $(\mathrm{M}+\mathrm{G}+\mathrm{B})$, $\mathrm{sob}$ seis níveis de nitrogênio $\left(\mathrm{kg} \mathrm{ha}^{-1}\right)$

\begin{tabular}{|c|c|c|c|c|c|}
\hline \multicolumn{6}{|c|}{ Número de grãos por fileira (NGF) } \\
\hline Doses & MS & $\mathrm{M}+\mathrm{G}$ & $\mathrm{M}+\mathrm{B}$ & $\mathrm{M}+\mathrm{G}+\mathrm{B}$ & Média \\
\hline 0 & $26 \mathrm{c} \mathrm{B}$ & 33 a $\mathrm{A}$ & $34 \mathrm{ab} A$ & 37 a A & $32 \mathrm{~b}$ \\
\hline 40 & 34 abc $\mathrm{A}$ & 36 a $\mathrm{A}$ & 39 a A & 32 a $\mathrm{A}$ & $35 \mathrm{ab}$ \\
\hline 80 & $37 \mathrm{ab} \mathrm{AB}$ & 39 a A & $30 \mathrm{~b} \mathrm{~B}$ & 40 a $\mathrm{A}$ & $37 \mathrm{a}$ \\
\hline 120 & $30 \mathrm{bc} \mathrm{B}$ & 38 a $\mathrm{A}$ & $37 \mathrm{ab} \mathrm{AB}$ & 34 a $\mathrm{AB}$ & $35 \mathrm{ab}$ \\
\hline 160 & $36 \mathrm{ab} A$ & 34 a $\mathrm{A}$ & $37 \mathrm{ab} A$ & 35 a $\mathrm{A}$ & $36 \mathrm{ab}$ \\
\hline 200 & 40 a $\mathrm{A}$ & 38 a $\mathrm{A}$ & 41 a $\mathrm{A}$ & 36 a $\mathrm{A}$ & 39 a \\
\hline Média & $34 \mathrm{~A}$ & $36 \mathrm{~A}$ & $37 \mathrm{~A}$ & $36 \mathrm{~A}$ & \\
\hline
\end{tabular}

Médias seguidas da mesma letra maiúscula na linha ou minúscula na coluna, não diferem entre si estatisticamente a 5\% pelo teste de Tukey. 
Com relação aos valores médios obtidos com as diferentes doses de $\mathrm{N}$ observou-se que, na ausência do fornecimento do $\mathrm{N}$ em cobertura, e ainda nas doses de 40, 120 e $160 \mathrm{~kg} \mathrm{ha}^{-1}$ não foram observadas diferenças significativas, concordando com Aguiar et al. (2012) ao observarem que não houve diferenças significativas entre alto (144 $\mathrm{kg} \mathrm{ha}^{-1}$ ) e baixo N. Observando-se as doses aplicadas em relação aos consórcios, para a dose de $40 \mathrm{~kg} \mathrm{ha}^{-1}$, apenas milho + guandu + braquiária $(\mathrm{M}+\mathrm{G}+\mathrm{B})$ foi estatisticamente inferior aos demais, já na maior dose, o milho + braquiária $(\mathrm{M}+\mathrm{B})$ foi superior aos demais com $211 \mathrm{~mm}$ e o milho + guandu $(\mathrm{M}+\mathrm{G})$ foi o que obteve a menor média $177 \mathrm{~mm}$.

As crescentes doses de nitrogênio fornecidas em cobertura atuaram positivamente sobre a média de número de grãos por fileira, causando diferença significativa entre a maior $\left(200 \mathrm{~kg} \mathrm{ha}^{-1}\right)$ com média de 39 e a menor $\left(0 \mathrm{~kg} \mathrm{ha}^{-1}\right)$ com 32 grãos por fileira, neste caso, o uso de $80 \mathrm{~kg} \mathrm{ha}^{-1}$ de $\mathrm{N}$ também obteve a média mais próxima da maior dose, confirmando a possibilidade de utilização de doses intermediárias para este genótipo (Tabela 3 ) indicando que variedades podem responder a doses intermediárias e também ao aumento destas.

Carmo et al. (2012) observaram que com o aumento nas doses de $\mathrm{N}$, aumentaram também os valores número de grãos por fileira, com doses de $\mathrm{N}$ de $(0,50,100$, $150 \mathrm{~kg} \mathrm{ha}^{-1}$ ) parecidas com as utilizadas neste trabalho, estes autores também observaram resposta linear para o número de grãos por fileira.

Silva et al. (2005) concluíram que o incremento da dose de $\mathrm{N}$ aplicada proporcionou aumento no número de grãos por fileira, atingindo o ponto de máxima eficiência técnica com a dose $154 \mathrm{~kg} \mathrm{ha}^{-1}$ de N. Meira et al. (2009) obtiveram média de 37,17 grãos por fileira utilizando até $120 \mathrm{~kg} \mathrm{ha}^{-1}$ de nitrogênio na forma de sulfato de amônio, e a média entre as doses encontrada neste trabalho foi de 36 grãos por fileira.

Nomilho solteiro(MS) sem a aplicação deNem cobertura, a média de NGF foi de 26 e de 40 no tratamento de 200 $\mathrm{kg} \mathrm{ha}^{-1}$ de $\mathrm{N}$ e nas médias em milho + braquiária $(\mathrm{M}+\mathrm{B})$ observou-se que a maior dose de $\mathrm{N}$ também foi a que possibilitou a maiores NGF, com 41 grãos/fileira, em milho + guandu $(\mathrm{M}+\mathrm{G})$ e milho + guandu + braquiária $(\mathrm{M}+\mathrm{G}+\mathrm{B})$ não houve diferenças significativas entre as médias.

Entre os consórcios não foi observada diferença significativa para NGF, Barducci et al. (2009) observaram que houve interação entre os sistemas de cultivo e doses de nitrogênio a $1 \%$ de significância pelo teste $\mathrm{F}$, os quais utilizaram também o sistema de cultivo do milho com Brachiaria brizantha cv. Marandu, consorciada na semeadura e a adubação de cobertura nas doses de 0 , 30,60 e $120 \mathrm{~kg} \mathrm{ha}^{-1}$, concordando com a presente pesquisa, que ao semear simultaneamente milho e Brachiaria decumbens houve interação entre doses e consórcio. Porém ao optar pelo consórcio deve-se atentar a densidade de plantas, visto que esta influencia significativamente o número de grãos por fileira (Marchão et al., 2005).

A maior dose utilizada $\left(200 \mathrm{~kg} \mathrm{ha}^{-1}\right)$, proporcionou média de 285 gramas por planta (Tabela 4), independentemente do consórcio, estando próxima da dose utilizada por Ferreira et al. (2001) que foi 199,6 $\mathrm{kg} \mathrm{ha}^{-1}$ resultando no peso das espigas com palha de $11480 \mathrm{~kg} \mathrm{ha}^{-1}$, superando a presente pesquisa em apenas $80 \mathrm{~kg} \mathrm{ha}^{-1}(0,7 \%)$ na produção estimada, porém, cabe

Tabela 3 - Médias para número de grãos por fileira para diferentes consórcios: milho solteiro (MS); milho com feijão-guandu $(\mathrm{M}+\mathrm{G})$; milho com braquiária $(\mathrm{M}+\mathrm{B})$; e milho com feijão-guandu e braquiária $(\mathrm{M}+\mathrm{G}+\mathrm{B})$, sob seis níveis de nitrogênio $\left(\mathrm{kg} \mathrm{ha}^{-1}\right)$

\begin{tabular}{|c|c|c|c|c|c|}
\hline \multicolumn{6}{|c|}{ Número de grãos por fileira (NGF) } \\
\hline Doses & MS & $\mathrm{M}+\mathrm{G}$ & $\mathrm{M}+\mathrm{B}$ & $\mathrm{M}+\mathrm{G}+\mathrm{B}$ & Média \\
\hline 0 & $26 \mathrm{c} \mathrm{B}$ & 33 a $\mathrm{A}$ & $34 \mathrm{ab} A$ & 37 a $\mathrm{A}$ & $32 \mathrm{~b}$ \\
\hline 40 & 34 abc $A$ & 36 a A & 39 a $A$ & 32 a $\mathrm{A}$ & $35 \mathrm{ab}$ \\
\hline 80 & $37 \mathrm{ab} \mathrm{AB}$ & 39 a A & $30 \mathrm{~b} \mathrm{~B}$ & 40 a $\mathrm{A}$ & $37 \mathrm{a}$ \\
\hline 120 & $30 \mathrm{bc} \mathrm{B}$ & 38 a $\mathrm{A}$ & $37 \mathrm{ab} \mathrm{AB}$ & 34 a $\mathrm{AB}$ & $35 \mathrm{ab}$ \\
\hline 160 & $36 \mathrm{ab} \mathrm{A}$ & 34 a A & $37 \mathrm{ab} A$ & 35 a $\mathrm{A}$ & $36 \mathrm{ab}$ \\
\hline 200 & 40 a $A$ & 38 a $\mathrm{A}$ & 41 a $\mathrm{A}$ & 36 a $\mathrm{A}$ & 39 a \\
\hline Média & $34 \mathrm{~A}$ & $36 \mathrm{~A}$ & $37 \mathrm{~A}$ & $36 \mathrm{~A}$ & \\
\hline
\end{tabular}

Médias seguidas da mesma letra maiúscula na linha ou minúscula na coluna, não diferem entre si estatisticamente a $5 \%$ pelo teste de Tukey. 
Tabela 4 - Médias para peso de espigas com palha para diferentes consórcios: milho solteiro (MS); milho com feijão-guandu $(\mathrm{M}+\mathrm{G})$; milho com braquiária $(\mathrm{M}+\mathrm{B})$; e milho com feijão-guandu e Braquiária $(\mathrm{M}+\mathrm{G}+\mathrm{B})$, sob seis níveis de nitrogênio $\left(\mathrm{kg} \mathrm{ha}^{-1}\right)$

\begin{tabular}{lccccc}
\hline \multicolumn{5}{c}{ Número de grãos por fileira (NGF) } \\
\hline Doses & MS & M+G & M+B & M+G+B & Média \\
\hline 0 & 178 & 210 & 233 & 209 & 232 \\
40 & 229 & 230 & 273 & $\mathrm{~b}$ \\
80 & 198 & 257 & 268 & 280 & $241 \mathrm{ab}$ \\
120 & 243 & 263 & 266 & 287 & $262 \mathrm{a}$ \\
160 & 277 & 285 & 241 & 283 & $263 \mathrm{a}$ \\
200 & 288 & $249 \mathrm{~A}$ & $260 \mathrm{~A}$ & $262 \mathrm{~A}$ & $285 \mathrm{a}$ \\
\hline
\end{tabular}

Médias seguidas da mesma letra maiúscula na linha ou minúscula na coluna, não diferem entre si estatisticamente a $5 \%$ pelo teste de Tukey.

ressaltar que nessa dose utilizou-se sementes de uma população aberta de milho, indicando uma resposta adequada ao aumento de nitrogênio disponível.

Lucena et al. (2000) utilizando diferentes doses de $\mathrm{N}\left(80,120\right.$ e $\left.160 \mathrm{~kg} \mathrm{ha}^{-1} \mathrm{de} \mathrm{N}\right)$, obtiveram valores de peso de espigas com palha superiores a dose de $40 \mathrm{~kg}$ $\mathrm{ha}^{-1}$, evidenciando que para esta variável o maior suprimento nitrogenado mostrou-se positivo, porém dividindo as doses em dois grupos. Nesta pesquisa peso de espigas com palha (PECP) aumentou linearmente, atingindo uma taxa de incremento de $0,33 \mathrm{~g}$ de espiga por planta a cada quilo de $\mathrm{N}$ aplicado por hectare (Figura 1).

Doses iguais ou superiores a $40 \mathrm{~kg} \mathrm{ha}^{-1}$ não mostraram diferenças da maior dose aplicada, porém foi somente a partir da dose de $120 \mathrm{~kg} \mathrm{ha}^{-1}$ que as médias de PECP foram superiores a encontrada com a dose 0 , sintomas de deficiência como clorose e aumento da senescência foram observados no campo, nas parcelas sem o suprimento de nitrogênio (Jakelaitis et al., 2005).

Nota-se, na média das doses de nitrogênio, que os diferentes tipos de plantios simultâneos e também o milho solteiro, não influenciaram significativamente a característica de peso de espigas com palha. Este fato indica a possibilidade de inclusão de outras espécies, em uma mesma área, e ao mesmo tempo, aumentando a eficiência de uso da área, sem prejuízo para a cultura principal, concordando com Pereira et al. (2011) ao usarem o híbrido AG1051 notaram que apresentou produtividade de grãos semelhantes em monocultivo e no consórcio com Crotalaria juncea.

Kappes et al. (2009) observaram que as fontes de nitrogênio utilizadas (sulfato de amônio, ureia e



Figura 1 - Influência das doses de $\mathrm{N}$ em cobertura, na média dos consórcios, sobre o peso de espigas com palha. $* *$ “b” Significativo a $1 \%$ pelo teste t.

entec) na dose de $70 \mathrm{~kg} \mathrm{ha}^{-1}$ apresentaram influência significativa, para a característica diâmetro de sabugo, em comparação com os tratamentos que não receberam o nutriente em cobertura, porém, entre as fontes, não houve diferença significativa. Essa característica pode explicar o maior incremento no "b" (PECP 0,3324 e PG $=0,2023)$ encontrado para o peso de espigas com palha (PECP) em relação ao peso de grãos (PG) para cada quilo de nitrogênio aplicado por hectare.

O peso dos grãos (PG) variou de acordo com o nitrogênio, onde as maiores doses $(120,160$ e $200 \mathrm{~kg}$ $\mathrm{ha}^{-1}$ ) obtiveram médias superiores a dose $0 \mathrm{~kg} \mathrm{ha}^{-1}$, já quando se utilizou 40 e $80 \mathrm{~kg} \mathrm{ha}^{-1}$ não houve diferença das demais médias (Tabela 5). 
Silva et al. (2003) verificaram que utilizando a maior dose de nitrogênio ( $\left.120 \mathrm{~kg} \mathrm{ha}^{-1}\right)$, houve aumento no crescimento da planta e nos rendimentos de espigas verdes e de grãos, devido a maior disponibilidade deste nutriente. Jakelaitis et al. (2005) confirmaram que o rendimento de grãos foi afetado pelo aumento das doses de $\mathrm{N}$ em cobertura, e ainda Basi et al. (2011) observaram que o nitrogênio apresenta estreita relação com a produtividade de grãos e de matéria seca da parte aérea da planta de milho.

Ohland et al. (2005) comparando médias de produtividade de grãos de milho dos tratamentos com adição de $\mathrm{N}$, em relação ao tratamento na ausência deste, constataram que foi significativa para todas as doses aplicadas, sendo estas, $(0,50,100,150$ e 200 $\mathrm{kg}$ de $\mathrm{N} \mathrm{ha}^{-1}$ ) e que, a dose de $200 \mathrm{~kg} \mathrm{ha}^{-1}$ de $\mathrm{N}$ em cobertura promoveu o maior acréscimo de produtividade na cultura do milho, mostrando que a adição de nitrogênio eleva a produtividade de grãos, similar ao presente trabalho, onde fornecendo $200 \mathrm{~kg}$ ha- ${ }^{1}$ a média foi de 176 gramas por planta. Porém deve-se atentar ao fato de que, conforme Mar et al. (2003), com doses altas podem ocorrer maiores perdas de $\mathrm{N}$.

Segundo Jakelaitis et al. (2005), nos tratamentos consorciados com Brachiaria brizantha, a adição de cada $\mathrm{kg} \mathrm{ha}^{-1}$ de $\mathrm{N}$ em cobertura incrementou-se 10,47 $\mathrm{kg} \mathrm{ha}^{-1} \mathrm{o}$ rendimento de grãos, sendo que as maiores produtividades foram obtidas com a utilização das doses mais elevadas de nitrogênio, gerando um efeito linear positivo das doses de $\mathrm{N}$ sobre o rendimento de grãos, valor próximo ao encontrado neste trabalho, onde o incremento no rendimento de grãos foi de $8,49 \mathrm{~kg}$ ha${ }^{1}$ para cada $\mathrm{kg} \mathrm{ha}^{-1}$ de nitrogênio adicionado.
Com relação aos consórcios, em nenhuma das características analisadas houve significância, havendo comportamento similar para esta variável independentemente do sistema de cultivo. Foi possível observar ainda que as médias encontradas em PG foram semelhantes às de PECP havendo diferença apenas entre as doses 120,160 e $200 \mathrm{~kg} \mathrm{ha}^{-1} \mathrm{em}$ relação à dose $0 \mathrm{~kg} \mathrm{ha}^{-1}$, já os tratamentos 40 e $80 \mathrm{~kg} \mathrm{ha}^{-1}$ não diferiram dos demais. Outra semelhança encontrada nos resultados das variáveis de produção foi à ausência de efeito dos consórcios, confirmando a possibilidade melhor aproveitamento da área, sem prejuízo à cultura principal (Figura 2).

\section{CONCLUSÕES}

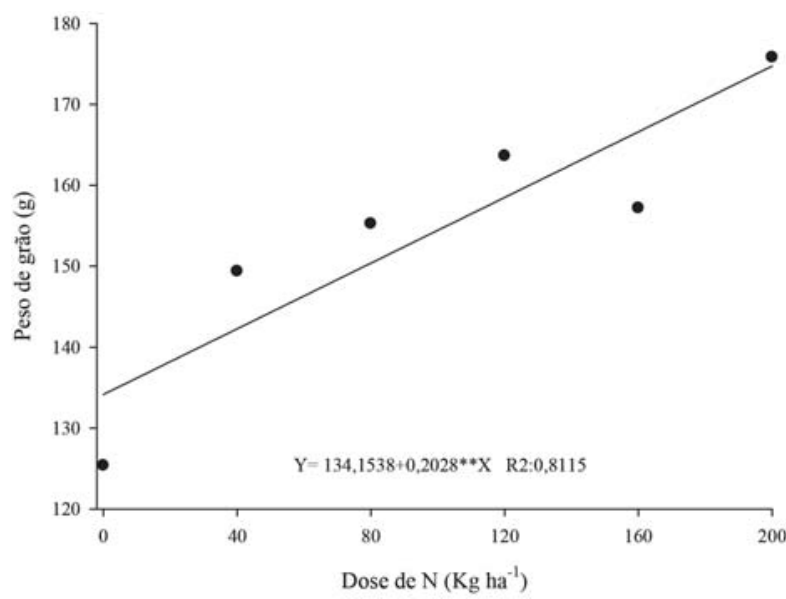

Figura 2- Influência das doses de $\mathrm{N}$ em cobertura, na média dos consórcios, sobre o peso de grãos. ** "b" Significativo a $1 \%$ pelo teste t.

Tabela 5 - Médias para peso de grãos para diferentes consórcios: milho solteiro (MS); milho com feijão-guandu $(\mathrm{M}+\mathrm{G})$; milho com braquiária $(\mathrm{M}+\mathrm{B})$; e milho com feijão-guandu e braquiária $(\mathrm{M}+\mathrm{G}+\mathrm{B})$, sob seis níveis de nitrogênio (kg ha-1).

\begin{tabular}{lccccc}
\hline & \multicolumn{4}{c}{ Número de grãos por fileira (NGF) } \\
\hline Doses & MS & M+G & M+B & M+G+B & Média \\
\hline 200 & 181 & 171 & 179 & 172 & 176 \\
120 & 156 & 157 & 165 & 169 & $163 \mathrm{a}$ \\
160 & 168 & 146 & 145 & 168 & $157 \mathrm{a}$ \\
80 & 152 & 158 & 165 & 131 & $149 \mathrm{ab}$ \\
40 & 143 & 117 & 149 & 129 & $125 \mathrm{~b}$ \\
0 & 106 & $149 \mathrm{~A}$ & $159 \mathrm{~A}$ & $159 \mathrm{~A}$ \\
\hline
\end{tabular}

Médias seguidas da mesma letra maiúscula na linha ou minúscula na coluna, não diferem entre si estatisticamente a 5\% pelo teste de Tukey. 
As doses de $\mathrm{N}$ influenciaram no comprimento de espiga, número de grãos por fileira, peso de espiga com palha e peso de grão.

As variáveis, peso de espiga com palha e peso de grão apresentaram valores médios similares, porém com maior influência da dose de nitrogênio para peso de espiga com palha.

Os consórcios não influenciaram nas variáveis analisadas, no plantio simultâneo com o milho, sem afetá-lo, na média das doses nitrogenadas.

\section{AGRADECIMENTOS}

Ao Programa de Pós-graduação em Produção Vegetal da Universidade Federal do Tocantins - UFT e Coordenação de Aperfeiçoamento de Pessoal de Nível Superior - CAPES.

\section{LITERATURA CITADA}

AGUIAR, C. B. N.; COIMBRA, R. R.; AFERRI, F. S.; PAULA, M. J.; FREITAS, M. K. C.; OLIVEIRA, R. J. Desempenho agronômico de híbridos de milho verde em função da adubação nitrogenada de cobertura. Revista Ciências Agrárias, v. 55, n. 1, p. 11-16, jan./mar. 2012. Disponível em: $<$ http://www.periodicos.ufra.edu.br/index.php/ ajaes/article/viewArticle/352>

AMADO, T. J. C.; MIELNICZUK, J.; AITA, C. Recomendação de adubação nitrogenada para o milho no RS e SC adaptada ao uso de culturas de cobertura do solo, sob sistema plantio direto, Revista Brasileira de Ciência do Solo, v. 26, p. 241-248, 2002. Disponível em:<http:// sbcs.solos.ufv.br/solos/revistas/v26n1a25.pdf>

ANDRADE, M. J. B.; MORAIS, A. R.; TEIXEIRA, T. R.; SILVA, M. V. Avaliação de sistemas de consórcio de feijão com milho-pipoca, Ciência e Agrotecnologia, v. 25, n. 2, p. 242-250, mar./ abr., 2001 .

BARDUCCI, R.S.; COSTA, C.; CRUSCIOL, C. A. C.; BORGHI, É.; PUTAROV, T. C.; SARTI. L. M. N. Produção de Brachiaria brizantha e Panicum maximum com milho e adubação nitrogenada, Archivos de Zootecnia, v. 58, n. 222, jun. 2009. DOI:dx.doi.org/ $10.4321 / \mathrm{S} 0004-05922009000200006$
BASI, S.; NEUMANN, M.; MARAFON, F.; UENO, R. K.; SANDINI, I. E. Influência da adubação nitrogenada sobre a qualidade da silagem de milho. Revista Brasileira de Tecnologia Aplicada nas Ciências Agrárias, v. 4, n. 3, p. 219-234, 2011. Disponível em:< http://revistas.unicentro.br/ index.php/repaa/article/view/1433/1587>

BORGHI, E.; CRUSCIOL, C. A. C. Produtividade de milho, espaçamento e modalidade de consorciação com Brachiaria briazantha em sistema plantio direto, Pesquisa Agropecuária Brasileira, v. 42, n. 2, p. 163-171, fev. 2007.

CARMO, M. S.; CRUZ, S. C. S.; SOUZA, E. J.; CAMPOS, L. F. C.; MACHADO, C. G. Doses e fontes de nitrogênio no desenvolvimento e produtividade da cultura de milho doce (Zea mays convar. saccharata var. rugosa), Bioscience Journal, v. 28, Supplement 1, p. 223-231, Mar. 2012.

CRUZ, S. C. S.; PEREIRA, F. R. S.; BICUDO, S. J.; ALBUQUERQUE, A. W.; SANTOS, J. R.; MACHADO, C. G. Nutrição do milho e da Brachiaria decumbens cultivados em consórcio em diferentes preparos do solo. Acta Scientiarum. Agronomy, v. 30, p. 733-739, 2008.

DUETE, R. R. C.; MURAOKA, T.; SILVA, E. C.; TRIVELIN, P. C. O.; AMBROSANO, E. J. Manejo da adubação nitrogenada e utilização do nitrogênio (15 N) pelo milho em Latossolo Vermelho. Revista Brasileira de Ciência do Solo, Campinas, v. 32, n. 1, p. 161-171, 2008. DOI:dx.doi.org/10.1590/ S0100-06832008000100016

FERREIRA, A. C. B.; ARAÚJO, G. A. A.; PEREIRA, P. R. G.; CARDOSO, A. A. Características agronômicas e nutricionais do milho adubado com nitrogênio, molibdênio e zinco, Scientia Agricola, v.58, n.1, p.131-138, 2001.

FERREIRA, D. F. Sisvar: a computer statistical analysis system. Ciência e Agrotecnologia (UFLA), v. 35, n. 6, p. 1039-1042, 2011. DOI: dx.doi.org/10.1590/S1413-70542011000600001

GOMES R. F., SILVA, A. G.; ASSIS, R. L.; PIRES, F. R. Efeito de doses e da época de aplicação de nitrogênio nos caracteres agronômicos da cultura do milho sob plantio direto. Revista Brasileira de Ciência do Solo, Viçosa, v. 31, n. 5, p. 931-938, 2007. DOI: dx.doi.org/10.1590/S0100-06832007000500010 
HEINRICHS, R.; VITTI, G. C.; MOREIRA, A.; FANCELLI, A. L. Produção e estado nutricional do milho em cultivo intercalar com adubos verdes, Revista Brasileira de Ciências do Solo, v. 26, p. 225-230, 2002.

JAKELAITIS, A.; SILVA, A. A.; FERREIRA, L. R. Efeitos do nitrogênio sobre o milho cultivado em consórcio com Brachiaria brizantha, Acta

Scientiarum. Agronomy, v. 27, n. 1, p. 39-46, 2005.

KAPPES, C.; CARVALHO, M. A. C.;

YAMASHITA, O. M.; SILVA, J. A. N. Influência do nitrogênio no desempenho produtivo do milho cultivado na segunda safra em sucessão à soja,

Pesquisa Agropecuária Tropical, v. 39, n. 3, p. 251-259, 2009.

LUCENA, L. F. C.; OLIVEIRA, F. A.; SILVA, I. F.; ANDRADE, A. Resposta do milho a diferentes dosagens de nitrogênio e fósforo aplicados ao solo. Revista Brasileira de Engenharia Agrícola e Ambiental, vol.4, n.3, p. 334-337, 2000.

MACHADO FILHO, G. C.; SILVA, F. R.; Benefícios sociais, econômicos e ambientais dos sistemas agroflorestais (SAFs) em pequenas propriedades rurais. Inclusão Social, v. 6, n. 1, 2013.

MACHADO FILHO, G. C.; NASCIMENTO, I. R.; SAKAI, T. R. P.; ROCHA, W. S.; SANTOS, M. M. dos. ${ }^{\circ}$ Brix e produção de espigas de milho verde em função de épocas de adubação nitrogenada.

Pesquisa Aplicada \& Agrotecnologia, Guarapuava-PR, v.11, n.1, p.33-41, jan-abr., 2018. DOI: 10.5935/PAeT.V11.N1.04

MAR, G. D.; MARCHETTI, M. E.; SOUZA, L. C. F.; GONÇALVES, M. C.; NOVELINO, J. O.

Fertilidade do solo e nutrição de plantas, produção do milho safrinha em função de doses e épocas de aplicação de nitrogênio, Bragantia, v.62, n.2, p. 267-274, 2003.
MARCHÃO, R. L., BRASIL, E. M.; DUARTE, J. B.; GUIMARÃES, C. M.; GOMES, J. A. Densidade de plantas e características agronômicas de híbridos de milho sob espaçamento reduzido entre linhas. Pesquisa Agropecuária Tropical, v. 35, n. 2, p. 93$101,2005$.

OHLAND, R. A. A.; SOUZA, L. C. F.; HERNANI, L. C.; MARCHETTI, M. E.; GONÇALVES, M. C. Culturas de cobertura do solo e adubação nitrogenada no milho em plantio direto, Ciência e Agrotecnologia, v. 29, n. 3, p. 538-544, maio/jun., 2005.

PEREIRA, L. C.; FONTANETTI, A.; BATISTA, J. N.; GALVÃO, J. C. C.; GOULART, P. L. Comportamento de cultivares de milho consorciados com Crotalaria juncea: estudo preliminar. Revista Brasileira de Agroecologia, v. 6, n. 3, p. 191-200, 2011.

RICHART, A.; PASLAUSKI, T.; NOZAKI, M. H.; RODRIGUES, C. M.; FEY, R. Desempenho do milho safrinha e da Brachiaria ruziziensis cv. comum em consórcio, Revista Brasileira Ciências Agrárias, v. 5, n. 4, p. 497-502, 2010.

SILVA, E. C.; BUZETTI, S.; GUIMARÃES, G. L.; LAZARINI, E.; SÁ, M. E. Seção IV - Fertilidade do solo e nutrição de plantas doses e épocas de aplicação de nitrogênio na cultura do milho em plantio direto sobre latossolo vermelho,

Revista Brasileira Ciência do Solo, v. 29, n. 3, p. 353-362, 2005.

SILVA, P. S. L.; OLIVEIRA, F. H. T.; SILVA, P. I. B. Efeitos da aplicação de doses de nitrogênio e densidades de plantio sobre os rendimentos de espigas verdes e de grãos de milho.

Horticultura Brasileira, v. 21, n. 3, p. $452-$ $455,2003$.

Recebido para publicação em 24/9/2017 e aprovado em 3/9/2018. 